\title{
Effect of Ammonia Concentration on Shortcut Nitrification and Denitrification
}

\author{
$\mathrm{Na} \mathrm{Li}{ }^{1,2, a}$, Xiaomin $\mathrm{Hu}^{1, b, *}$, Guode $\mathrm{Li}^{2, c}$, Xin Zhao ${ }^{1, \mathrm{~d}}$ \\ ${ }^{1}$ School of Resources and Civil Engineering, Northeastern University, Shenyang 110004, P.R.China \\ ${ }^{2}$ Experimental Center of Shenyang Normal University, Shenyang 110034, P.R.China \\ alina218@126.com, bhxmin_jj@163.com, cliguode@synu.edu.cn, dzx06_cn@163.com \\ ${ }^{*}$ Corresponding Author
}

Keywords: MBBR; ammonia concentration; shortcut nitrification and denitrification

Abstract. In this examination we have experimented the effect of ammonia concentration on shortcut nitrification and denitrification in a moving bed biofilm reactor (MBBR). The results show that, when the influent ammonia concentration slowly increased to $200 \mathrm{mg} / \mathrm{L}$, the ammonia removal rate and the nitrite accumulation rate were respectively $92.7 \%$ and $84.2 \%$, which were better than that of other influent ammonia concentration. And when the influent ammonia concentration was $200 \mathrm{mg} / \mathrm{L}$, the average TN removal rate was also better than other influent ammonia concentration, which was $56.0 \%$. The TN removal rate increased first and then decreased with the influent ammonia concentration increase.

\section{Introduction}

With the rapid development of social economy and the acceleration of urbanization, the problems existing in wastewater treatment have been exposed[1]. Removal of nitrogen pollutant is an important aspect of wastewater treatment[2]. Nitrogen contained in wastewater is a pervasive and serious aquatic problem, known as eutrophication that causes excessive growth of algae and cyanobacteria[3-4]. Wastewater denitrification is gaining increasing attention. The traditional biological nitrogen removal process has high energy consumption, long reaction time and high sludge yield[5]. It is urgent to develop a highly efficient biological nitrogen removal process for the current water pollution situation. reduce energy costs and improve treatment efficiency. Shortcut nitrification and denitrification can reduce oxygen demand and organic source demand by up to $25 \%$ and $40 \%$, respectively[6-7]. The shortcut nitrification and denitrification process is a hot topic in the study of biological nitrogen removal.

The development and use of a moving bed biofilm reactor (MBBR) has evolved to treat a broad range of wastewaters[8]. MBBRs have significantly lower suspended solids production and can reduce the space compared to traditional activated sludge system, can increase solid retention time for slow growing organisms, and can rapidly recover from extreme loading conditions[9]. In this study, MBBR was combined with shortcut nitrification and denitrification to study the effect of influent ammonia concentration on shortcut nitrification and denitrification in a MBBR reactor.

\section{Materials and Methods}

Configuration of the MBBR. The equipment process was shown in Fig.1. The peristaltic pump continuously pumps the waste water from the inlet into the bottom of the reactor, and the treated water overflows through the top hole of the reactor. The bottom of the reaction device has a microporous sand core aeration head to ensure sufficient dissolved oxygen and to make the filler fluidized. Aeration is controlled by a rotor flowmeter. The device is provided with partition boards from the bottom aerator head and the top water outlet $5 \mathrm{~cm}$ to prevent the filler from blocking the sewage outlet and the water outlet. The top cover of the reactor is equipped with adjustable speed mixer, stirring and aeration alternately during operation. By aerobic aeration and anoxic stirring alternately run in the 
MBBR to better achieve short-cut nitrification and denitrification. The device has a temperature and $\mathrm{pH}$ sensor system that automatically regulates the temperature and automatically doses the $\mathrm{pH}$.

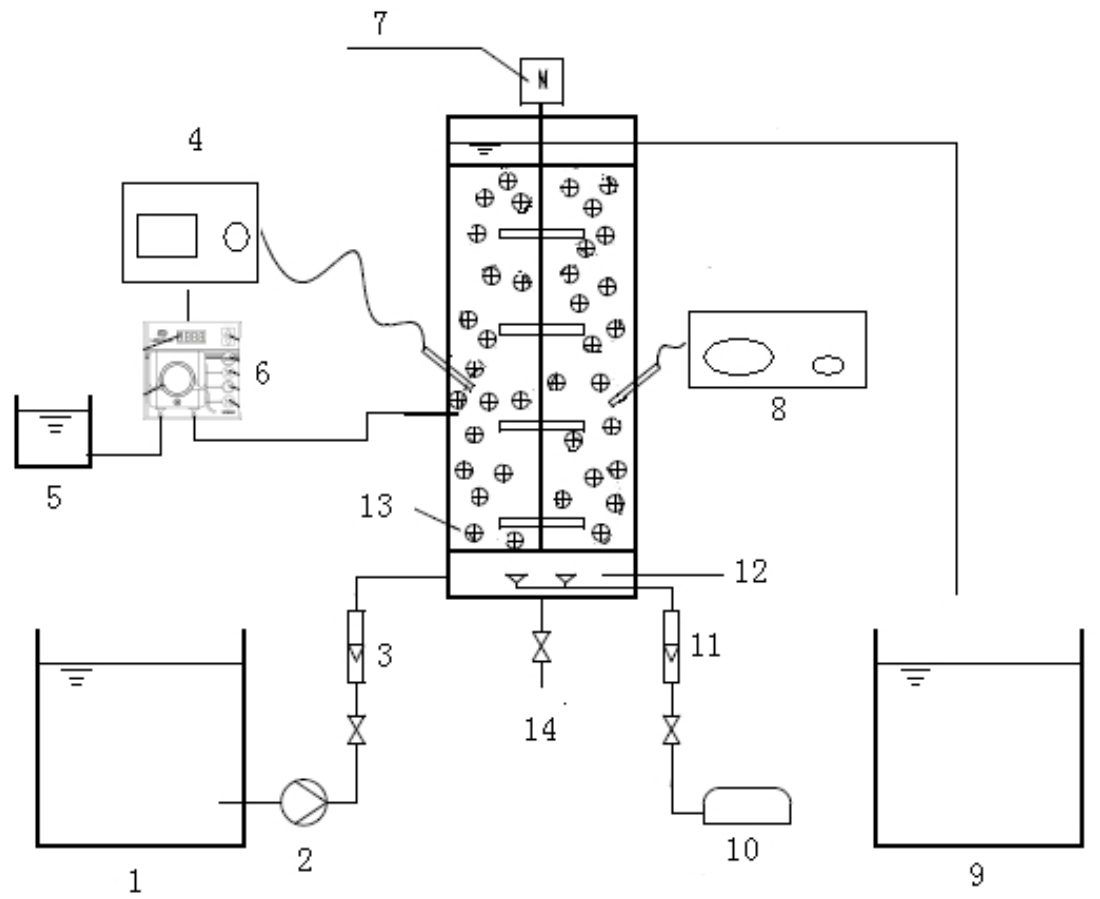

1.Ifluent; 2.Intelligent constant-flow pump; 3.Inlet flowmeter; 4. $\mathrm{pH}$ online monitor; 5.Dosing box;

6.Dosing persitaltic pump; 7.Variable frequency mixing motor; 8.Temperature Controller;

9.Effluent; 10.Air pump; 11.Gas flowmeter; 12.Aeration header; 13.Filler; 14.Drain valve

Fig.1 Experiment technological process

Synthetic wastewater. $\mathrm{NH}_{4} \mathrm{Cl}$ and $\mathrm{C}_{6} \mathrm{H}_{12} \mathrm{O}_{6}$ were respectively used as nitrogen and carbon source in the synthetic wastewater. The synthetic wastewater also contained $\mathrm{NaHCO}_{3}(400 \mathrm{mg} / \mathrm{L}), \mathrm{CaCl}_{2}$ $(4 \mathrm{mg} / \mathrm{L}), \mathrm{KH}_{2} \mathrm{PO}_{4}(40 \mathrm{mg} / \mathrm{L}), \mathrm{MgSO}_{4} \cdot 7 \mathrm{H}_{2} \mathrm{O}(40 \mathrm{mg} / \mathrm{L})$ and trace elements: $\mathrm{FeCl}_{3}(375 \mathrm{mg} / \mathrm{L}), \mathrm{H}_{3} \mathrm{BO}_{3}$ $(37.5 \mathrm{mg} / \mathrm{L}), \quad \mathrm{CuSO}_{4} \cdot 5 \mathrm{H}_{2} \mathrm{O}(7.5 \mathrm{mg} / \mathrm{L}), \quad \mathrm{KI}(45 \mathrm{mg} / \mathrm{L}), \quad \mathrm{MnSO}_{4} \cdot \mathrm{H}_{2} \mathrm{O}(25.69 \mathrm{mg} / \mathrm{L}), \mathrm{ZnSO}_{4} \cdot 7 \mathrm{H}_{2} \mathrm{O}$ $(30 \mathrm{mg} / \mathrm{L})$, EDTA $(2500 \mathrm{mg} / \mathrm{L}), \mathrm{CoCl}_{2} \cdot 6 \mathrm{H}_{2} \mathrm{O}(50 \mathrm{mg} / \mathrm{L}), \mathrm{Na}_{2} \mathrm{MoO}_{4} \cdot 2 \mathrm{H}_{2} \mathrm{O}(20 \mathrm{mg} / \mathrm{L})$.

Inoculated sludge characteristics. The inoculated sludge was taken from South Wastewater Treatment Plant (Shenyang, China). Characteristics of inoculated sludge were tabulated in Table 1.

Table 1. Characteristics of inoculated sludge

\begin{tabular}{cccc}
\hline Parameter & SVI $\left[\mathrm{mL} \cdot \mathrm{g}^{-1}\right]$ & MLSS $\left[\mathrm{mg} \cdot \mathrm{L}^{-1}\right]$ & $\mathrm{VSS}\left[\mathrm{mg} \cdot \mathrm{L}^{-1}\right]$ \\
\hline Value & 67.72 & 4430 & 3340 \\
\hline
\end{tabular}

Analytical methods. MLSS and MLVSS were determined with the gravimetric method according to the standard protocol of State Environmental Protection Administration of China [10]. $\mathrm{pH}$ was measured with a METTLER TOLEDO pH meter-FE20 (China). DO was detected with a HACH HQ30d Dissolved Oxygen Meter (USA). Concentrations of the effluent nitrogen compounds and $\mathrm{COD}, \mathrm{BOD}_{5}$ were also determined according to the protocol of State Environmental Protection Administration of China .The analytical methods above were shown in Table 2. 
Table 2. Analytical methods of experimental wastewater quality

\begin{tabular}{cc}
\hline Parameter & Method \\
\hline $\mathrm{pH}$ & FE20 pH meter (METTLER TOLEDO, China) \\
$\mathrm{DO}$ & HQ30d DO meter (HACH Company, USA) \\
$\mathrm{COD}$ & DR3900 COD meter (HACH Company, USA) \\
$\mathrm{BOD}_{5}$ & BODTrakTM (Hach Company, USA) \\
$\mathrm{NH}_{4}^{+}-\mathrm{N}$ & Nesster's reagent colorimetry \\
$\mathrm{NO}_{2}^{-}-\mathrm{N}$ & $\mathrm{N}-(1-$ naphthyl) ethylenediamine \\
$\mathrm{NO}_{3}^{-}-\mathrm{N}$ & spectrophotometric method \\
$\mathrm{MLSS}$ & ultraviolet spectrophotometry \\
$\mathrm{MLVSS}$ & weight measurement method \\
\hline
\end{tabular}

\section{Results and discussion}

Starting up and acclimation. The filler used in this experiment was Dalian Yudu (China) modified bio-suspended filler, the filling rate was $50 \%$. The inoculated sludge was taken from the sewage treatment plant in southern Shenyang, China, and after being acclimated the sludge was put into the reactor to operation. Take the quick discharge method to fill the film. After nearly 20 days stable operation, the filler has a layer of brown biofilm, meanwhile the average COD removal rate and average ammonia removal rate were respectively $85 \%$ and $65 \%$, indicating that the filler film was successful. Keep the water quality unchanged, through the regulation of dissolved oxygen to achieve shortcut nitrification and denitrification.

Effect of influent ammonia concentration on nitrogen removal. The aeration rate in the system was constant, DO was $2.0 \mathrm{mg} / \mathrm{L}$ or more, room temperature. In order to investigate the effects of different ammonia concentration, the influent ammonia concentration increased from $50 \mathrm{mg} / \mathrm{L}$ to 300 $\mathrm{mg} / \mathrm{L}$, and with the increase of ammonia concentration, HRT increased from $8 \mathrm{~h}$ to $48 \mathrm{~h}$. The concentration of ammonia was changed to $50 \mathrm{mg} / \mathrm{L}, 100 \mathrm{mg} / \mathrm{L}, 150 \mathrm{mg} / \mathrm{L}, 200 \mathrm{mg} / \mathrm{L}$ and $300 \mathrm{mg} / \mathrm{L}$ respectively, and the water quality was measured continuously for 10 days after the system was stable.

With the increase of ammonia concentration, the change of nitrogen is shown in Fig.2. During the whole experiment, the average nitrite accumulation rate was $68.3 \%$, that is, with the increase of ammonia concentration, the system was in shortcut nitrification. However, the nitrate concentration increased with the ammonia concentration increase, that was because the reaction substrate $\mathrm{NO}_{2}^{-}-\mathrm{N}$ increased when influent ammonia concentration increase, which lead to reaction rate increased. But the system has been in short cut nitrification, so the ammonia oxidizing bacteria in the system have been in advantage. When the concentration of ammonia was $50 \mathrm{mg} / \mathrm{L}$, the average removal rate of ammonia was $97.6 \%$, the average nitrite accumulation rate was $77.9 \%$, the system treatment was stable and the operation was good. When the influent ammonia concentration was increased to 100 $\mathrm{mg} / \mathrm{L}$, by the impact of ammonia load, the average ammonia removal rate and the average nitrite accumulation rate were decreased to $68.6 \%$ and $68.3 \%$ respectively. Then we changed the way of ammonia concentration increasing, slowly increased the influent ammonia concentration and enhance the training of the system, adjusted the HRT. When the concentration of ammonia was $150 \mathrm{mg} / \mathrm{L}$, the removal rate of ammonia nitrogen was higher than that of $100 \mathrm{mg} / \mathrm{L}$, the average removal rate of ammonia was $82.5 \%$, and the average nitrite accumulation rate increased to $74.9 \%$. When the concentration of ammonia was $200 \mathrm{mg} / \mathrm{L}$, the average removal rate of ammonia and average nitrite accumulation rate were respectively $92.7 \%$ and $84.2 \%$. When the concentration of ammonia increased to $300 \mathrm{mg} / \mathrm{L}$, the average removal rate of ammonia nitrogen changed little, which was $92.2 \%$. The reasons are as follows, With the increase of ammonia concentration, the demand for ammonia-oxidizing bacteria increases, and the increase of ammonia concentration in the influent will inevitably lead to the increase of free ammonia concentration, and the free ammonia will inhibit the 
ammonia-oxidizing bacteria, and the ammonia removal rate did not continue to increase. The average nitrite accumulation rate decreased slightly, which was $78.5 \%$.

The removal of total nitrogen under different influent ammonia concentrations was shown in Fig.3. When the concentration of ammonia was $50 \mathrm{mg} / \mathrm{L}, 100 \mathrm{mg} / \mathrm{L}, 150 \mathrm{mg} / \mathrm{L}, 200 \mathrm{mg} / \mathrm{L}$ and $300 \mathrm{mg} / \mathrm{L}$, the average TN removal rates were respectively $44.6 \%, 47.1 \%, 51.9 \%, 56.0 \%$ and $52.5 \%$. During the whole experiment, the denitrification effect was the best when the concentration of ammonia was 200 $\mathrm{mg} / \mathrm{L}$, and the average removal rate of TN was the highest. From the removal of total nitrogen, it can be seen that the removal rate of total nitrogen increased first and then decreased with the increase of ammonia concentration.

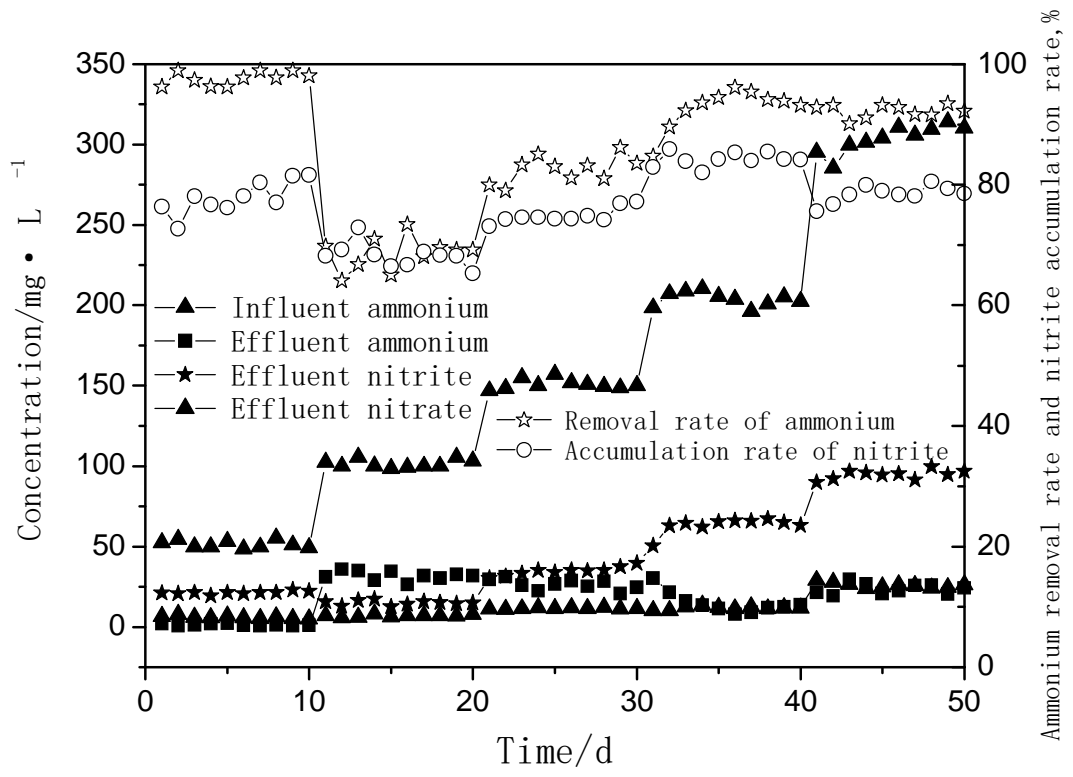

Fig. $2 \mathrm{NH}_{4}{ }^{+}-\mathrm{N}, \mathrm{NO}_{2}{ }^{-}-\mathrm{N}$ and $\mathrm{NO}_{3}{ }^{-}-\mathrm{N}$ changed with ammonia loading

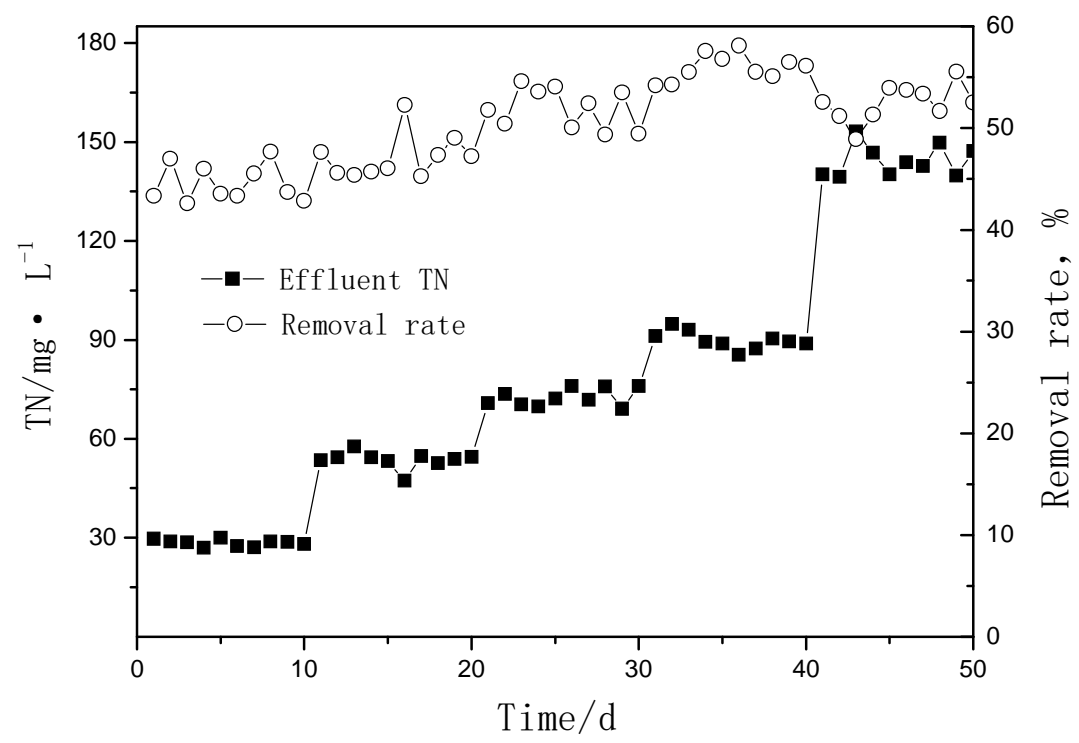

Fig.3 TN changed with ammonia loading

\section{Conclusions}

When the influent ammonia concentration was $50 \mathrm{mg} / \mathrm{L}$, the average ammonia removal rate and nitrite accumulation rate were respectively $97.64 \%, 77.9 \%$, and the system treatment effect was stable. When the influent ammonia concentration increased slowly to $200 \mathrm{mg} / \mathrm{L}$, the average ammonia 
removal rate and average nitrite accumulation rate were respectively $92.7 \%$ and $84.2 \%$. When the influent ammonia concentration increased to $300 \mathrm{mg} / \mathrm{L}$, The average removal rate of ammonia nitrogen changed little, which was $92.2 \%$, and the average accumulation rate of nitrite decreased to $78.5 \%$. When the influent ammonia concentration was $200 \mathrm{mg} / \mathrm{L}$, denitrification was the best. At this time, the average total nitrogen removal rate was $56 \%$. The total nitrogen removal rate increased first and then decreased with the increase of influent ammonia concentration.

\section{Acknowledgements}

This work was financially supported by the Liaoning Provincial Natural Science Foundation Project, (201602683) , China; Liaoning Province large equipment sharing service platform capacity building fund project (2015), China; Shenyang Science and Technology Project, (F15-199-1-21), China ; Provincial College Students Innovation and Entrepreneurship Training Program (201710166045), China; College Students' Innovative Entrepreneurship Training Program Level (20171016620073), China.

\section{References}

[1] Y.L. Suo, J. Pan, Y.Q. Chen: Journal of Shenyang Normal University (Natural Science) Vol.25 (2007), p.376 [in Chinese]

[2] Leonidia Maria Castro Daniel, Eloísa Pozzi and Eugenio Foresti et al.: Bioresource Technology Vol. 100 (2009), p. 1100

[3] S.J. Ge, S.Y. Wang and X. Yang et al.: Chemosphere Vol. 140 (2015), p. 85

[4] M.T. Oguz, K. G. Robinson and A.C. Layton et al.: Biotechnology and Bioengineering Vol. 97 (2007), p. 1562

[5] T. Bai, H. Lei and G.W. Yu et al.: Process Safety and Environmental Protection Vol. 87 (2009), p. 307

[6] O. Canals, H. Salvado and M. Auset et al.: Water Research Vol. 47 (2013), p. 3141

[7] F.H. Cui, S. Lee and M. Kim: Water Research Vol. 45 (2011), p. 5279

[7] J.L. Shore, W.S. and M'Coy et al.: Bioresource Technology Vol. 112 (2012), p. 51

[9] A. Pervissian, W.J. Parker, and R.L. Legge: Environmental Progress \& Sustainable Energy Vol. 31 (2012), p. 288

[10] F.S. Wei, in: Chinese Water and Wastewater Monitoring Methods 4th ed edn, edtied by Chinese Environmental Science Publishing House, China (2002), in press. 